\title{
Do arterial resections improve survival in pancreatic cancer? -a narrative review
}

\author{
Artur Rebelo, Ulrich Ronellenfitsch, Jessica Döbereiner, Jörg Ukkat, Jörg Kleeff \\ Department of Visceral, Vascular and Endocrine Surgery, University Hospital Halle (Saale), Martin-Luther-University Halle-Wittenberg, Halle, \\ Germany \\ Contributions: (I) Conception and design: A Rebelo, U Ronellenfitsch, J Kleeff; (II) Administrative support: J Ukkat, J Kleeff; (III) Provision of \\ study materials or patients: U Ronellenfitsch, J Döbereiner; (IV) Collection and assembly of data: A Rebelo, J Döbereiner; (V) Data analysis and \\ interpretation: All authors; (VI) Manuscript writing: All authors; (VII) Final approval of manuscript: All authors. \\ Correspondence to: Jörg Kleeff, MD, FACS, FRCS. Professor of Surgery and Chairman, Department of Visceral, Vascular and Endocrine \\ Surgery, University Hospital Halle (Saale), Martin-Luther-University Halle-Wittenberg, Ernst-Grube-Str. 40, 06120 Halle (Saale), Germany. \\ Email: joerg.kleeff@uk-halle.de.
}

Objective: In this article, we outline the important features of pancreatic cancer surgery in cases with visceral artery encasement.

Background: Despite recent advances in diagnosis and treatment, pancreatic cancer continues to have a poor prognosis. Due to its limited response to chemotherapies, radiation, or targeted therapies, surgery (in combination with adjuvant chemotherapy) is the only potential way to treat pancreatic cancer in a curative manner. As only about $20 \%$ of the patients have surgically resectable disease at the time of diagnosis, the resection of encased visceral veins and arteries, along with neoadjuvant regimens, is one approach to treat otherwise palliative patients.

Methods: Based on a selective literature review, we discuss the results of several studies and meta-analyses, comparing the mortality and morbidity, as well as long-term survival in patients undergoing arterial resection vs standard treatment. We conducted a selective literature review in PubMed without restrictions regarding time of publication or study design. Only articles in English language were selected.

Conclusions: Several studies and meta-analyses comparing resection with and without arterial resection and reconstruction showed a significantly higher post-operative mortality and morbidity and shorter long-term survival in patients who required arterial resection. In patients with tumors initially considered irresectable, the approach of neoadjuvant chemotherapy followed by resection with arterial reconstruction showed a significantly increased survival compared to palliative chemotherapy alone with acceptable postoperative morbidity. Tumor resection with arterial reconstruction following intensive preoperative chemotherapy (plus radiochemotherapy in some cases) should be considered in selected patients, as it can prolong survival and potentially lead to sustained freedom from tumor recurrence.

Keywords: Arterial resection; pancreatic cancer; pancreatic surgery; vascular

Submitted Apr 09, 2021. Accepted for publication Jul 01, 2021.

doi: 10.21037/cco-21-39

View this article at: https://dx.doi.org/10.21037/cco-21-39

\section{Introduction}

Pancreatic cancer is one of the few tumor entities with further increasing incidence. Despite all the advances in modern medicine, it continues to have a poor prognosis. In 2020, pancreatic cancer accounted for $2.6 \%$ new cancer cases and $4.7 \%$ of cancer deaths worldwide, making it the seventh leading cause of cancer-related deaths (1). Although diagnosis and treatment have improved over the past years, the overall 5 -year survival still remains at around $9 \%$ (2). The main difficulty in the treatment of 
pancreatic cancer lies in the late detection of most cases, due to the unspecific symptoms caused by it, the early local spreading through perineural and venous invasion, and its rapid (metastatic) progression (3). The generally poor response to chemotherapies, radiation, or targeted therapies marks another obstacle, making surgery (in combination with adjuvant chemotherapy) the only potential way to treat pancreatic cancer in a curative manner. At the time of diagnosis, only about $20 \%$ of patients have a surgically resectable disease (4). Along with neoadjuvant regimens, the resection of encased visceral veins and arteries in patients with borderline resectable or locally unresectable disease is one approach to treat otherwise palliative patients.

This literature review will provide an overview on current evidence regarding the staging and risk assessment of pancreatic cancer with arterial invasion, possible treatment options and their technical details, and their effect on relevant outcomes. We present the following article in accordance with the Narrative Review reporting checklist (available at https://dx.doi.org/10.21037/cco-21-39).

\section{Methods}

We conducted a selective literature review in PubMed without restrictions regarding time of publication or study design. Only fully published articles in English language were selected.

\section{Discussion}

\section{Staging of locally advanced pancreatic cancer with suspected arterial contact or invasion}

Thin-sliced (maximum slice thickness $0.3 \mathrm{~cm}$ ) multiphase computed tomography is the first-line imaging modality in diagnosing and staging pancreatic cancer and offers the best information concerning tumor resectability especially with regard to locally advanced tumors with suspected vascular tumor contact or invasion. Magnetic resonance tomography is usually reserved for liver imaging to confirm or rule out hepatic metastases, and for cases with equivocal findings in computed tomography (5). Positron emission tomography (PET) is also highly sensitive in diagnosing pancreatic masses, but lacks the resolution to adequately stage the disease and determine resectability with regard to adjacent vascular structures (6).

Laboratory findings are mostly unspecific for local tumor extension and vascular invasion. A tumor marker connected to pancreatic cancer is CA 19-9. Though it cannot be used alone for diagnosis, it has a prognostic value and is helpful in monitoring the disease during and after treatment (7). In case of cholestasis due to other causes, however, CA 19-9 can be high without an underlying pancreatic cancer.

To complete staging postoperatively, histological workup of the surgical specimen is necessary. It gives necessary information about the resection margins (R0-R2), grading (G1-G4) and histopathological type. Pancreatic ductal adenocarcinomas represent by far the largest group with about $90 \%$ of all pancreatic neoplasms (8).

\section{General considerations for treatment}

Curative treatment of pancreatic cancer is only possible by complete resection of the tumor and the regional lymph nodes. Complete (R0) resection margins are often difficult to achieve given the perineural growth pattern towards the retroperitoneum and surrounding major visceral arteries. While gross incomplete (R2) resection undoubtedly is associated with shorter survival, the relative benefit of R0 over microscopically incomplete (R1) resection has been a matter of debate. In earlier cohorts, a clear survival advantage for R0 over R1 resections could frequently not be shown. In hindsight, this is probably attributable to the heterogeneity of patients and resection approaches as well as differences in histopathological examination (9). Later studies on more homogenous cohorts showed that R0 resections improved survival compared with $\mathrm{R} 1$ resections, at least if the distance of tumor cells to the margin was $>1 \mathrm{~mm}(9,10)$. Some analyses showed that achieving an R0 margin is particular important for pancreatic head and less so for pancreatic corpus and tail tumors (11). For carcinomas with extensive nodal metastases, an $\mathrm{R} 0$ resection might not be as important regarding survival compared to more limited disease $(12,13)$.

Adjuvant chemotherapy has now become standard of care for virtually all stages of pancreatic adenocarcinoma resected in curative intent. While already less potent regimens such as 5-fluorouracil plus folinic acid or gemcitabine monotherapy have been shown to prolong survival (14), intensive combination therapy such as FOLFIRINOX is even more beneficial regarding survival. Consequently, it has become the standard of care at least for patients with an adequate postoperative performance status and no relevant comorbidities precluding such a potentially toxic treatment (15). Yet, even for patients receiving adjuvant chemotherapy, R0 resection is important as it confers a survival benefit compared to $\mathrm{R} 1$ resection as demonstrated by a secondary analysis from a randomized controlled trial (16). This underlines that resection 


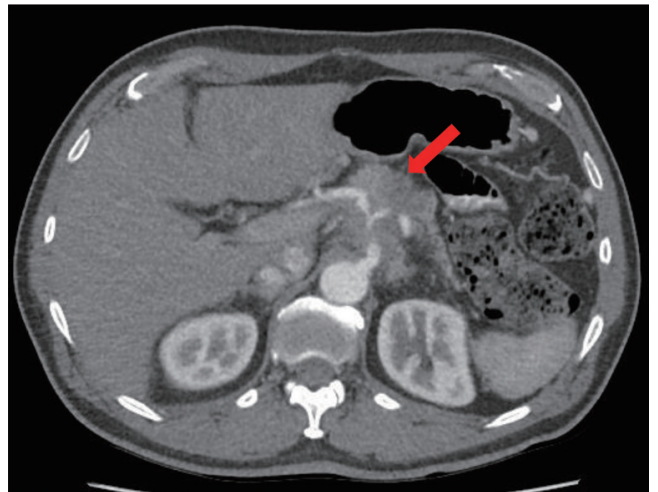

Figure 1 Irresectable pancreatic cancer, according to the international consensus classification (17). The tumor shows complete encasement of the celiac trunk (arrow).

of pancreatic cancer should only be attempted if there is a realistic chance of achieving tumor clearance.

\section{Definition of resectability}

A major obstacle to complete resection is the contact to or encasement of visceral arteries such as the celiac trunk (CT) or the superior mesenteric artery (SMA) by the tumor, which is present in up to $30 \%$ of patients at the time of diagnosis (17). An international consensus meeting developed a definition of when a tumor should be considered "borderline resectable" and when it should be considered irresectable (17). In terms of anatomy of the visceral arteries, the former is the case if there is a less than $180^{\circ}$ tumor contact to the SMA or CT and no deformity or stenosis, or if there is isolated tumor contact to the common hepatic artery without contact to the SMA or the proper hepatic artery. More extensive arterial affection is considered irresectable according to this definition (Figure 1). A borderline resectable pancreatic carcinoma is still at a relevant risk that resection margins are microscopically (R1) or even grossly involved (R2) upon attempting resection. Therefore, neoadjuvant chemotherapy, ideally with an intensified regimen such as FOLFIRINOX or gemcitabine/nab-paclitaxel should be considered with the aim of increasing the probability of an R0 resection in these patients (18). Such resection will often require resection and reconstruction of visceral veins and arteries as outlined below.

\section{Indication for arterial resection}

For tumors considered irresectable by the above-mentioned definition, palliative chemotherapy, combined with biliary drainage procedures or gastroenterostomy if needed, has long been the only treatment considered appropriate. However, also with the advent of more effective regimens like the ones used for neoadjuvant treatment, chemotherapy followed by an attempt to resect the tumor, has been proposed for selected patients. In such cases, complete resection can only be achieved by resection and reconstruction of visceral arteries. One novel approach, the feasibility of which is currently evaluated in an ongoing clinical trial (PREVADER, NCT04136769), is a therapeutic splitting. This means that visceral debranching, i.e., the reconstruction of visceral arteries invaded by the tumor for example with an iliac-hepatic or iliac-mesenteric bypass, is performed as a first treatment step. Patients then proceed to intensive combination chemotherapy before they finally undergo tumor resection (19).

\section{Types of arterial resection and reconstruction}

The visceral arteries that need to be resected in advanced pancreatic cancer if invaded, i.e., the SMA (Figure 2), and the common or proper hepatic artery as branches of the CT (Figure 3), are functional end arteries. For the common hepatic artery, this holds at least true in case of pancreatic head resection or total pancreatectomy with resection of the gastroduodenal artery, which could otherwise serve as collateral to maintain sufficient liver perfusion. Therefore, arterial reconstruction to ensure appropriate perfusion of the downstream organs liver and bowel is mandatory if visceral arteries are resected during pancreatic resection.

In case of suspected arterial invasion, surgery should start with the so-called "artery first" approach (20). This means that before carrying out irreversible steps of the operation mandating pancreatic resection, such as division of the pancreas, invasion of the respective arteries and the concomitant need for resection and reconstruction are assessed. The SMA can be approached from various directions (right and left supra- and inframesocolic, or through Kocher's maneuver), the choice of which should depend on the suspected site of involvement (21). Once the exact extent of invasion has been determined, the required resection and reconstruction can be decided on.

For short-segment invasions of up to two centimeters, resection with direct reconstruction by end-to-end anastomosis is usually possible if the ends of the resected artery have been sufficiently mobilized. However, excessive tension or kinking of the vessel needs to be strictly avoided in order to ensure patency. For longer-segment invasions, direct reconstruction is not possible. In such cases, an anatomic or, more frequently, extra-anatomic reconstruction needs 

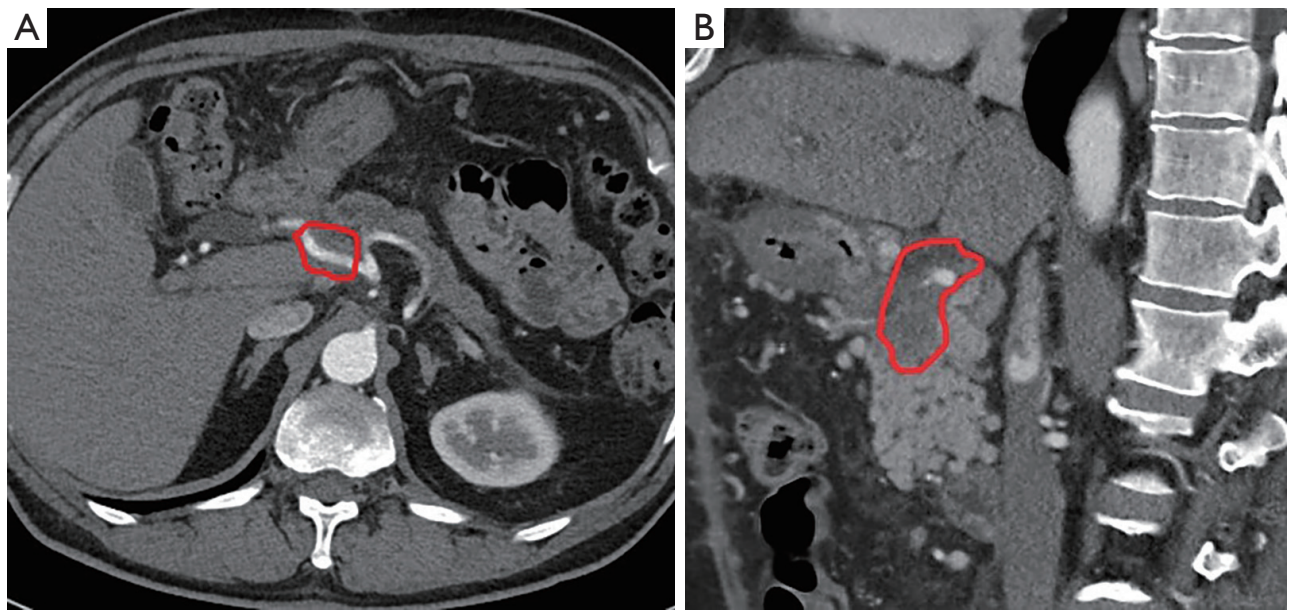

Figure 2 Carcinoma of the pancreatic head with $>180^{\circ}$ encasement of the proper hepatic artery. Axial (A) and sagittal (B) computed tomography reconstructions, tumor encircled in red.

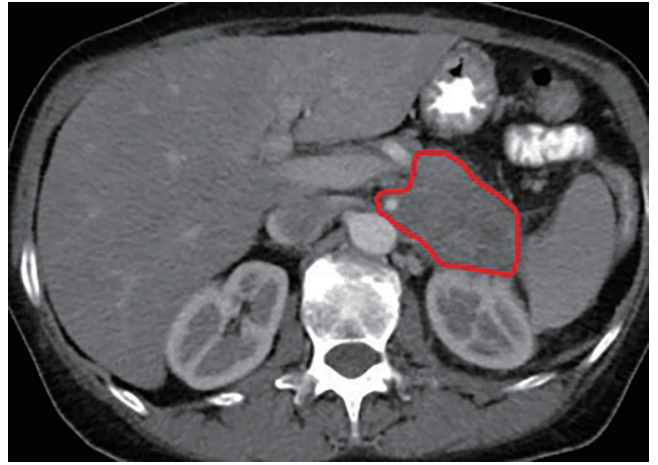

Figure 3 Large carcinoma of the pancreatic body and tail with $>180^{\circ}$ encasement of the superior mesenteric artery (axial computed tomography reconstruction, tumor encircled in red).

to be performed. Usually, this requires using a graft, which can either consist of an autologous vein such as the greater saphenous or the internal jugular vein (22), or an allogeneic prosthesis usually made of polytetrafluoroethylene (PTFE) or polyethylene terephthalate (PET, Dacron). Alternatively, the patient's splenic artery could be used for reconstruction either by transposition if the root of the CA is not affected, or by harvesting and interposition. However, both approaches require total pancreatectomy and splenectomy in order to allow dissection and mobilization of the splenic artery (23). The use of autologous graft material bears the risk of graft infection and a higher risk of erosion bleeding compared to autologous grafts, particularly so in case of postoperative pancreatic fistula. Therefore, some authors recommend

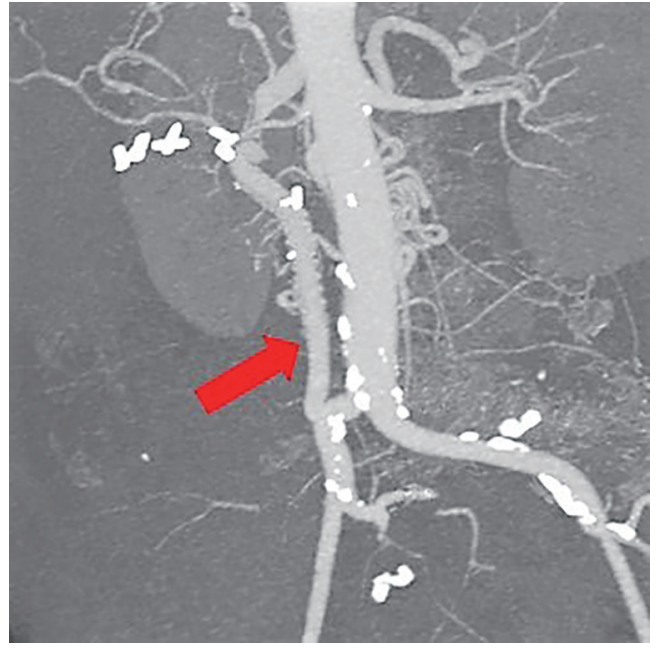

Figure 4 Multiplanar computed tomography reconstruction of a patient with an iliac-hepatic interposition graft $(6 \mathrm{~mm}$ PTFE ring enforced, arrow) used to maintain liver perfusion following pancreatoduodenectomy.

avoiding autologous material altogether or always performing total pancreatectomy if allogeneic grafts are used (21).

Anatomic reconstruction is carried out through an aortomesenteric or aorto-hepatic interposition or an interposition from the root of the resected visceral artery if this can be preserved with a sufficient length. This requires crossclamping of the aorta in the renovisceral segment and can be technically demanding particularly in obese patients. Extraanatomic reconstruction is most often done by allogeneous 

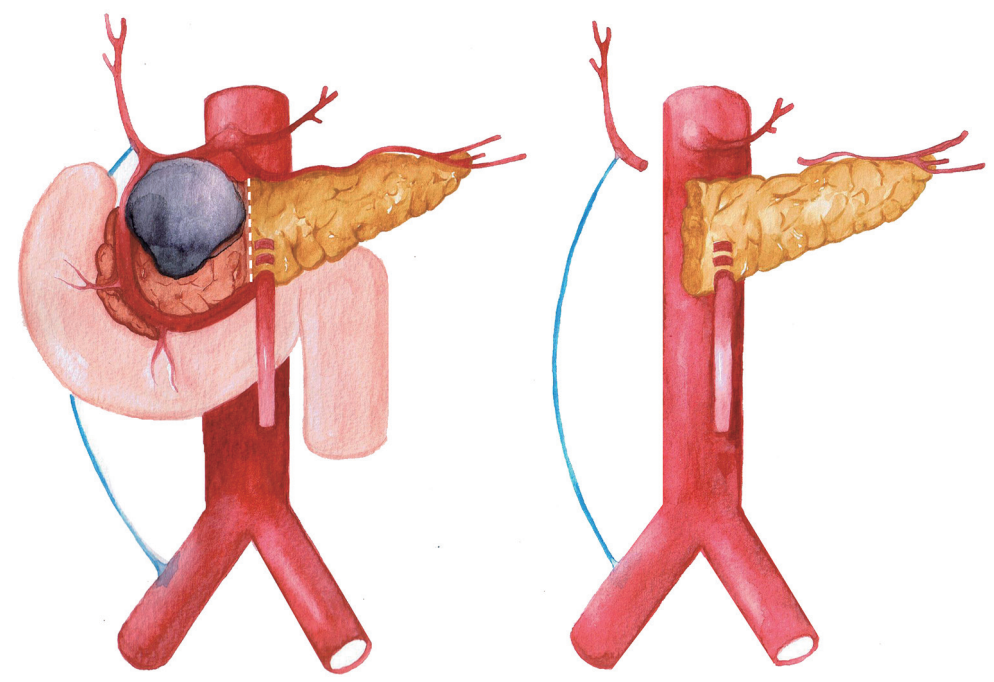

Figure 5 Illustration of a typical visceral debranching procedure: iliac-hepatic autologous vein bypass before (left) and after neoadjuvant chemotherapy and pancreatoduodenectomy (right) in a patient with a locally advanced carcinoma of the pancreatic head.
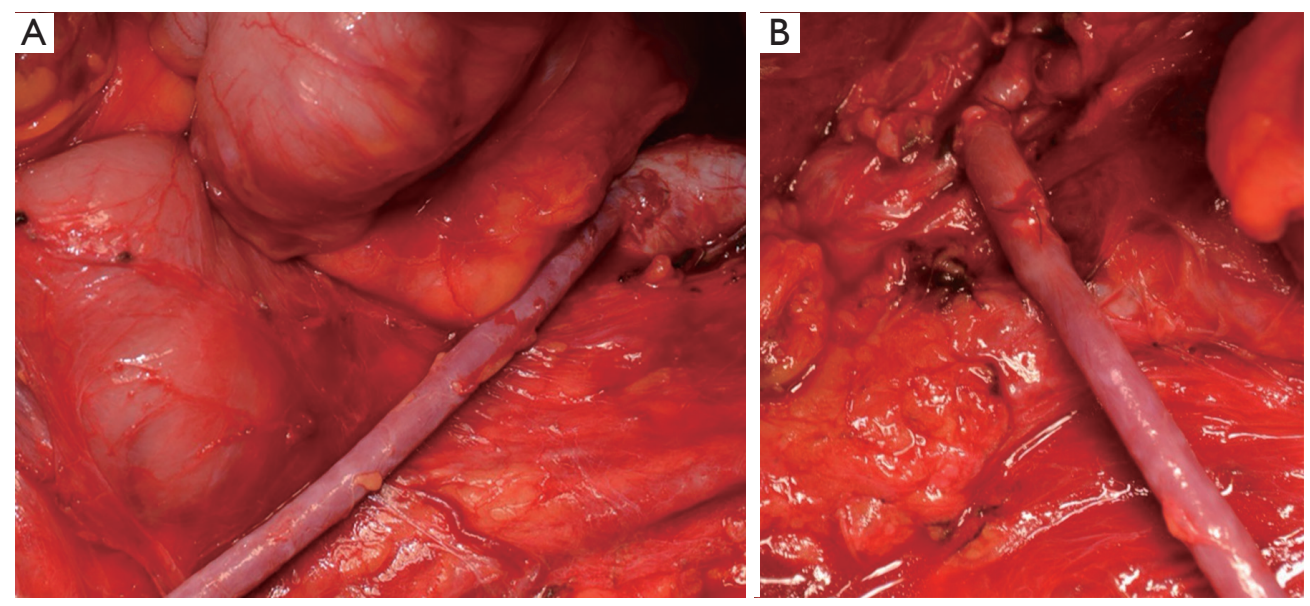

Figure 6 Iliac-hepatic autologous vein bypass using the greater saphenous vein: (A) iliac anastomosis, (B) hepatic anastomosis.

or autologous graft interposition from the infrarenal aorta or common iliac artery to the target visceral artery (Figures 4-6).

In the specific situation of distal pancreatectomy with CT resection, arterial resection without reconstruction can be done without compromising organ perfusion. This operation is sometimes referred to as "modified Appleby procedure" (24). The CT is resected at its origin eliminating antegrade flow to the common hepatic artery. Liver perfusion is maintained via gastroduodenal artery collateralisation. Intraoperatively, sufficient hepatic inflow should be ensured by Doppler sonographic flow measurement after test clamping of the common hepatic artery. As a means to enhance gastroduodenal collateral flow, preoperative embolization of the CT or common hepatic artery is suggested by some authors, although there is no conclusive evidence that this approach indeed improves subsequent liver perfusion $(25,26)$.

\section{Short- and long-term outcomes}

\section{Arterial resections vs. standard surgery}

Surgery for locally advanced pancreatic cancer with venous reconstruction can be performed with acceptable morbidity and mortality and is now widely established (27). In contrast, 
Table 1 Outcomes from studies on DP-CAR and SMA resection

\begin{tabular}{|c|c|c|c|c|c|c|c|c|c|}
\hline Reference & Year & Study type & $\begin{array}{l}\text { Type of } \\
\text { surgery }\end{array}$ & $\begin{array}{c}\text { Sample } \\
\text { size }\end{array}$ & $\begin{array}{c}\text { Mortality } \\
\text { rate (\%) }\end{array}$ & $\begin{array}{c}\text { Morbidity } \\
\text { rate (\%) }\end{array}$ & $\begin{array}{l}\text { Median survival } \\
\text { (months) }\end{array}$ & $\begin{array}{c}\text { 1-year survival } \\
(\%)\end{array}$ & $\begin{array}{l}\text { Ro rate } \\
(\%)\end{array}$ \\
\hline \multirow[t]{2}{*}{ Yamamoto et al. (31) } & 2018 & Retrospective & DP-CAR & 72 & 1.2 & 63 & 17.5 & 17 & 67 \\
\hline & & & $\mathrm{DP}$ & 323 & 4.2 & 47 & 28.6 & 40 & 80 \\
\hline Peters et al. (32) & 2016 & Prospective & DP-CAR & 17 & 0 & 5.9 & 20 & 75 & 82.4 \\
\hline \multirow[t]{2}{*}{ Perinel et al. (33) } & 2016 & Prospective & AR & 14 & 0 & 14 & 92 & 55 & 57 \\
\hline & & & No AR & 97 & 3 & 29 & 67 & 51 & 74 \\
\hline Klompmaker et al. (34) & 2016 & Retrospective & DP-CAR & 240 & 3.5 & 27 & 14.4 & - & 74.5 \\
\hline Klompmaker et al. (35) & 2018 & Retrospective & DP-CAR & 68 & 16 & 25 & 18 & 60 & 53 \\
\hline
\end{tabular}

DP, distal pancreatectomy; CAR, celiac axis resection; AR, arterial resection; SMA, superior mesenteric artery.

Table 2 Outcomes from meta-analyses on arterial resection $v s$. standard resection

\begin{tabular}{lllll}
\hline Reference & Year & Mortality & Morbidity & 1-year survival \\
\hline Mollberg et al. (36) & 2011 & $\begin{array}{l}\text { OR 5.04; 95\% Cl, 2.69-9.45; } \\
\mathrm{P}<0.0001\end{array}$ & $\begin{array}{l}\text { OR 2.17; 95\% Cl, 1.26-3.75; } \\
\mathrm{P}=0.006\end{array}$ & $\begin{array}{l}\text { OR 3.02; 95\% Cl, 1.13-8.11; } \\
\mathrm{P}=0.03\end{array}$ \\
Jegatheeswaran et al. (37) & 2017 & $20 \%$ & $39 \%$ to 91\% & - \\
Rebelo et al. (38) & 2020 & OR 2.55; 95\% Cl, 0.69, 9.42; & OR 1.15; 95\% Cl, 0.58-2.28; & OR 0.92; 95\% Cl, 0.41-2.09; \\
& & $\mathrm{P}=0.16$ & $\mathrm{P}=0.69$ & - \\
Małczak et al. (39) & 2020 & $\mathrm{RR} 4.09 ; \mathrm{P}<0.001$ & $\mathrm{RR} 1.4 ; \mathrm{P}=0.01$ & $59 \%$ \\
Haines et al. (40) & 2020 & $5 \%$ & $52 \%$ & 5 \\
\hline
\end{tabular}

the role of arterial resections in pancreatic surgery is still a matter of debate $(28,29)$. They were associated with high mortality rates in the past (30). Table 1 summarizes the outcomes of studies on arterial resections. In a retrospective study, 395 patients with pancreatic adenocarcinoma from seven high-volume centers in Japan who underwent distal pancreatectomy (DP) were investigated. Seventy-two patients underwent distal pancreatectomy with en bloc celiac axis resection (DP-CAR). The overall morbidity was significantly higher in the arterial resection group than in the standard group ( $63 \%$ vs. $47 \%, \mathrm{P}=0.02)$. The median survival time of the standard group was significantly longer than that of the arterial group (28.6 vs. 17.5 months, $\mathrm{P}<0.01)(31)$. In a matched analysis of 17 patients who underwent DPCAR were compared to 51 patients who underwent DP for pancreatic adenocarcinoma. Fifteen $(88.2 \%)$ patients who underwent DP-CAR had received neoadjuvant chemotherapy. The $\mathrm{R} 0$ resection rate was $82.4 \%$ after DP-CAR versus $92.2 \%$ after DP $(\mathrm{P}=0.36)$. Mortality, morbidity and median survival were not different between both groups (32). Another single center study from a high-volume center in France involved 14 patients who underwent pancreatic oncologic surgery with arterial resection and 97 patients with standard resection. Morbidity and mortality were not significantly different between the arterial resection and standard group ( $14 \%$ vs. $29 \%$ and $0 \%$ vs. $3 \%$ ), while R0 resection rate and 1 -year survival were $(57 \%$ vs. $74 \%, \mathrm{P}<0.01$ and $92 \%$ vs. 64\%, not significant) (33). A systematic review by Klompmaker et al. analysed 240 patients who underwent DP-CAR combined with (neo-) adjuvant chemotherapy and found a 90 -day mortality rate of $3.5 \%$. The overall median survival for the whole patient collective was 14.4 months (34). A retrospective cohort study from the same group included 68 patients from 20 hospitals in 12 countries and reported 30 - and 90-day mortality rates after DP-CAR of $10 \%$ and $16 \%$, respectively (35).

The available evidence has been synthesized by several meta-analyses (Table 2). In 2011, Mollberg et al. described a 
Table 3 Outcomes from studies comparing surgery to palliative treatments

\begin{tabular}{|c|c|c|c|c|c|c|c|c|c|}
\hline Reference & Year & Study type & Study type & Mortality & Morbidity & $\begin{array}{c}\text { 1-year } \\
\text { survival (\%) }\end{array}$ & $\begin{array}{c}\text { 3-year } \\
\text { survival (\%) }\end{array}$ & $\begin{array}{c}\text { 5-year } \\
\text { survival (\%) }\end{array}$ & $\begin{array}{l}\text { Overall } \\
\text { survival }\end{array}$ \\
\hline Satoi et al. (42) & 2013 & Retrospective & AR & - & - & 95 & 53 & 34 & - \\
\hline Gong et al. (43) & 2016 & $\begin{array}{l}\text { Systematic } \\
\text { review and } \\
\text { meta-analysis }\end{array}$ & $\begin{array}{l}\text { AR vs. } \\
\text { palliative }\end{array}$ & $\begin{array}{l}\text { OR } 1.80(95 \% \\
\mathrm{Cl}, 0.36-8.99)\end{array}$ & $\begin{array}{l}\text { OR } 2.11 \text { (95\% } \\
\mathrm{Cl}, 0.83-5.35)\end{array}$ & - & - & - & $\begin{array}{c}\text { OR } 0.38(95 \% \\
\text { Cl: } 0.25-0.58 \text {, } \\
\quad P<0.01)\end{array}$ \\
\hline \multirow[t]{2}{*}{ Del Chiaro et al. (44) } & 2019 & Retrospective & AR & $2.9 \%$ & $38.2 \%$ & 63.7 & 41.7 & 3.2 & - \\
\hline & & & Palliative & $2.6 \%$ & $25.6 \%$ & 23.4 & 23.4 & 0 & - \\
\hline
\end{tabular}

$\mathrm{AR}$, arterial resection.

high postoperative mortality after arterial resection (11.8\%). Arterial resections were also related to increased morbidity (53.6\%, OR: 2.17) and lower 1- and 3-year survival rates compared to patients without arterial resections (36). In 2017, Jegatheeswaran et al. performed a meta-analysis of the outcome of resection and reconstruction of the superior mesenteric artery (SMA) during surgery for pancreatic cancer. It included a total of 70 patients undergoing pancreatectomy with SMA resection and 10,726 undergoing the standard procedure. Peri-operative morbidity ranged from $39 \%$ to $91 \%$ and postoperative mortality was $20 \%$ (data from 25 patients) with a median survival of 11 months (37).

In a meta-analysis from 2020, Rebelo et al. included all contemporary relevant studies regarding arterial resection and reconstruction. A qualitative analysis with 841 patients with arterial resection was performed. Morbidity and mortality were $66.8 \%$ and $5.4 \%$, respectively, in patients undergoing arterial resection for pancreatic cancer. In the meta-analysis, 7 studies with a control group including patients undergoing standard resection were included. Overall morbidity and mortality were $48 \%$ vs. $39 \%$ and $3.2 \%$ vs. $1.5 \%$ in patients undergoing arterial resection $v s$. . patients without arterial resection. Weighted median survival was longer in patients who underwent a standard resection (32 vs. 18.6 months). Neoadjuvant treatment was associated with higher $\mathrm{R} 0$ resection rates and $\mathrm{R} 0$ rates were higher in the standard compared with the arterial resection group, both in patients without (69\% vs. $89 \%)$ and with neoadjuvant treatment ( $50 \%$ vs. $86 \%$ ) (38). In another meta-analysis from 2020, 19 studies were included in an analysis involving 2,710 patients. Arterial resection was associated with a higher risk of death (RR: 4.09; $\mathrm{P}<0.001)$ and morbidity (RR: 1.4; $\mathrm{P}=0.01$ ) and a shorter long-term survival (39). Also in 2020, Haines et al. performed a metaanalysis of 13 studies with 467 patients who underwent pancreatic surgery with arterial resection for pancreatic cancer. The median overall morbidity and 90 -day mortality were $52 \%$ and $5 \%$, respectively. The R0 rate was $66 \%$ and the median survival was 17 months with a 1 - and 3 -year survival of $59 \%$ and $17 \%$, respectively (40).

\section{Arterial resections vs. palliative treatments}

According to a national cohort study from the Dutch Pancreatic Cancer Group involving 36,453 patients with pancreatic ductal carcinoma, the 1-year survival of patients who received palliative chemotherapy improved along the last years from $13.3 \%$ to $21.2 \%(\mathrm{P}<0.001)(41)$. Therefore, it needs to be critically evaluated if arterial resection for locally advanced pancreatic cancer can in fact achieve longer overall survival. Table 3 shows outcomes from studies comparing surgery with arterial resection to palliative treatments. The Japanese Society of HepatoBiliary-Pancreatic Surgery analysed 58 patients with initially unresectable PDAC who underwent 8 months of neoadjuvant treatment followed by surgery. The approach resulted in clearly improved survival times compared to a palliative approach. The overall survival rates at 1,3 , and 5 years were $95 \%, 53 \%$, and $34 \%$ in the patients that underwent surgery and 88,18 , and $10 \%$ in the group with chemotherapy only. The survival time in the surgery group was significantly longer than in the chemotherapy group $(\mathrm{P}<0.001)(42)$. In a meta-analysis involving 18 studies, Gong et al. reported a higher 1-year survival rate for DPCAR compared to palliative treatments (pooled HR for OS $0.38,95 \%$ CI $0.25-0.58, \mathrm{P}<0.01$ ) (43). In 2019, Del Chiaro et al. analyzed 73 patients with borderline or locally 
advanced pancreatic cancer with arterial involvement. Thirty-four patients underwent an arterial resection and 39 underwent palliative surgery only. Post-operative mortality (2.9\% vs. $2.6 \%)$ and morbidity ( $38.2 \%$ vs. $25.6 \%)$ were not significantly different. The 1-, 3- and 5-year survival in the palliative group was inferior to the patients who underwent arterial resection $(63.7 \%, 23.4 \%$ and $23.4 \%$ vs. $41.7 \%, 3.2 \%$ and 0) (44).

\section{Summary}

Pancreatic cancer is despite all recent successes in diagnosis and treatment still a disease with high morbidity and short long-term survival. Potentially curative treatment is only possible with complete resection of the tumor and lymphonodal metastases, in combination with neoadjuvant and adjuvant chemotherapy. Studies have shown a significantly longer survival when $\mathrm{R} 0$ resection is achieved. One of the main obstacles to R0 resection is the partial or full encasement of visceral arteries by the tumor mass.

Several studies and meta-analyses comparing resection with and without arterial reconstruction showed a significantly higher post-operative mortality and morbidity and shorter long-term survival in patients who required arterial resection.

In patients whose tumors were initially considered irresectable, on the other hand, the approach of neoadjuvant chemotherapy followed by resection with arterial reconstruction showed a significantly increased survival compared to palliative chemotherapy. Single series comparing palliative surgery and resection with arterial reconstruction showed similar post-operative mortality and morbidity with higher 1-, 3- and 5-year survival rates after arterial resection.

In conclusion, resection with arterial reconstruction following intensive preoperative chemotherapy (in some cases plus radiochemotherapy) should be considered in selected patients because it can prolong survival and potentially lead to sustained freedom from tumor recurrence.

\section{Acknowledgments}

We thank Ms Paula Vieira for the illustrations. Funding: None.

\section{Footnote}

Provenance and Peer Review: This article was commissioned by the Guest Editor (Savio George Barreto) for the series
"Unresolved Issues in Pancreatic Cancer" published in Chinese Clinical Oncology. The article has undergone external peer review.

Reporting Checklist: The authors have completed the Narrative Review reporting checklist. Available at https:// dx.doi.org/10.21037/cco-21-39

Conflicts of Interest: All authors have completed the ICMJE uniform disclosure form (available at https://dx.doi. org/10.21037/cco-21-39). The series "Unresolved Issues in Pancreatic Cancer" was commissioned by the editorial office without any funding or sponsorship. The authors have no other conflicts of interest to declare.

Ethical Statement: The authors are accountable for all aspects of the work in ensuring that questions related to the accuracy or integrity of any part of the work are appropriately investigated and resolved.

Open Access Statement: This is an Open Access article distributed in accordance with the Creative Commons Attribution-NonCommercial-NoDerivs 4.0 International License (CC BY-NC-ND 4.0), which permits the noncommercial replication and distribution of the article with the strict proviso that no changes or edits are made and the original work is properly cited (including links to both the formal publication through the relevant DOI and the license). See: https://creativecommons.org/licenses/by-nc-nd/4.0/.

\section{References}

1. Sung H, Ferlay J, Siegel RL, et al. Global Cancer Statistics 2020: GLOBOCAN Estimates of Incidence and Mortality Worldwide for 36 Cancers in 185 Countries. CA Cancer J Clin 2021;71:209-49.

2. Rawla P, Sunkara T, Gaduputi V. Epidemiology of Pancreatic Cancer: Global Trends, Etiology and Risk Factors. World J Oncol 2019;10:10-27.

3. Hruban RH, Gaida MM, Thompson E, et al. Why is pancreatic cancer so deadly? The pathologist's view. J Pathol 2019;248:131-41.

4. Kleeff J, Korc M, Apte M, et al. Pancreatic cancer. Nat Rev Dis Primers 2016;2:16022.

5. Chu LC, Goggins MG, Fishman EK. Diagnosis and Detection of Pancreatic Cancer. Cancer J 2017;23:333-42.

6. Izuishi K, Yamamoto Y, Sano T, et al. Impact of 18-fluorodeoxyglucose positron emission tomography on 
the management of pancreatic cancer. J Gastrointest Surg 2010;14:1151-8.

7. Locker GY, Hamilton S, Harris J, et al. ASCO 2006 update of recommendations for the use of tumor markers in gastrointestinal cancer. J Clin Oncol 2006;24:5313-27.

8. Haeberle L, Esposito I. Pathology of pancreatic cancer. Transl Gastroenterol Hepatol 2019;4:50.

9. Konstantinidis IT, Warshaw AL, Allen JN, et al. Pancreatic ductal adenocarcinoma: is there a survival difference for R1 resections versus locally advanced unresectable tumors? What is a "true" R0 resection? Ann Surg 2013;257:731-6.

10. Tummers WS, Groen JV, Sibinga Mulder BG, et al. Impact of resection margin status on recurrence and survival in pancreatic cancer surgery. Br J Surg 2019;106:1055-65.

11. Demir IE, Jäger C, Schlitter AM, et al. R0 Versus R1 Resection Matters after Pancreaticoduodenectomy, and Less after Distal or Total Pancreatectomy for Pancreatic Cancer. Ann Surg 2018;268:1058-68.

12. Teske C, Stimpel R, Distler M, et al. Impact of resection margin status on survival in advanced $\mathrm{N}$ stage pancreatic cancer - a multi-institutional analysis. Langenbecks Arch Surg 2021. [Epub ahead of print]. doi: 10.1007/s00423021-02138-4.

13. Ghaneh P, Kleeff J, Halloran CM, et al. The Impact of Positive Resection Margins on Survival and Recurrence Following Resection and Adjuvant Chemotherapy for Pancreatic Ductal Adenocarcinoma. Ann Surg 2019;269:520-9

14. Sultana A, Cox T, Ghaneh P, et al. Adjuvant therapy for pancreatic cancer. Recent Results Cancer Res 2012;196:65-88.

15. Conroy T, Hammel P, Hebbar M, et al. FOLFIRINOX or Gemcitabine as Adjuvant Therapy for Pancreatic Cancer. N Engl J Med 2018;379:2395-406.

16. Vincent A, Herman J, Schulick R, et al. Pancreatic cancer. Lancet 2011;378:607-20.

17. Isaji S, Mizuno S, Windsor JA, et al. International consensus on definition and criteria of borderline resectable pancreatic ductal adenocarcinoma 2017. Pancreatology 2018;18:2-11.

18. Kaufmann B, Hartmann D, D'Haese JG, et al. Neoadjuvant Treatment for Borderline Resectable Pancreatic Ductal Adenocarcinoma. Dig Surg 2019;36:455-61.

19. Ronellenfitsch U, Michalski CW, Michl P, et al. Preoperative/Neoadjuvant Therapy and Vascular Debranching Followed by Resection for Locally Advanced Pancreatic Cancer (PREVADER): Clinical Feasibility Trial. Front
Med (Lausanne) 2021;8:588375.

20. Sanjay P, Takaori K, Govil S, et al. 'Artery-first' approaches to pancreatoduodenectomy. Br J Surg 2012;99:1027-35.

21. Klaiber U, Mihaljevic A, Hackert T. Radical pancreatic cancer surgery-with arterial resection. Transl Gastroenterol Hepatol 2019;4:8.

22. Maley WR, Yeo CJ. Vascular Resections During the Whipple Procedure. Adv Surg 2017;51:41-63.

23. Hackert T, Weitz J, Büchler MW. Splenic artery use for arterial reconstruction in pancreatic surgery. Langenbecks Arch Surg 2014;399:667-71.

24. Smoot RL, Donohue JH. Modified Appleby procedure for resection of tumors of the pancreatic body and tail with celiac axis involvement. J Gastrointest Surg 2012;16:2167-9.

25. Cesaretti M, Abdel-Rehim M, Barbier L, et al. Modified Appleby procedure for borderline resectable/ locally advanced distal pancreatic adenocarcinoma: A major procedure for selected patients. J Visc Surg 2016;153:173-81.

26. Kondo S, Katoh H, Shimizu T, et al. Preoperative embolization of the common hepatic artery in preparation for radical pancreatectomy for pancreas body cancer. Hepatogastroenterology 2000;47:1447-9.

27. Allendorf JD, Lauerman M, Bill A, et al. Neoadjuvant chemotherapy and radiation for patients with locally unresectable pancreatic adenocarcinoma: feasibility, efficacy, and survival. J Gastrointest Surg 2008;12:91-100.

28. Rebelo A, Michalski C, Ukkat J, Kleeff J. Pancreatic cancer surgery with vascular resection: current concepts and perspectives. Journal of Pancreatology 2019;2:1-5.

29. Oba A, Bao QR, Barnett CC, et al. Vascular Resections for Pancreatic Ductal Adenocarcinoma: Vascular Resections for PDAC. Scand J Surg 2020;109:18-28.

30. Stitzenberg KB, Watson JC, Roberts A, et al. Survival after pancreatectomy with major arterial resection and reconstruction. Ann Surg Oncol 2008;15:1399-406.

31. Yamamoto T, Satoi S, Kawai M, et al. Is distal pancreatectomy with en-bloc celiac axis resection effective for patients with locally advanced pancreatic ductal adenocarcinoma? -Multicenter surgical group study. Pancreatology 2018;18:106-13.

32. Peters NA, Javed AA, Cameron JL, et al. Modified Appleby Procedure for Pancreatic Adenocarcinoma: Does Improved Neoadjuvant Therapy Warrant Such an Aggressive Approach? Ann Surg Oncol 2016;23:3757-64.

33. Perinel J, Nappo G, El Bechwaty M, et al. Locally advanced pancreatic duct adenocarcinoma: pancreatectomy 
with planned arterial resection based on axial arterial encasement. Langenbecks Arch Surg 2016;401:1131-42.

34. Klompmaker S, de Rooij T, Korteweg JJ, et al. Systematic review of outcomes after distal pancreatectomy with coeliac axis resection for locally advanced pancreatic cancer. Br J Surg 2016;103:941-9.

35. Klompmaker S, van Hilst J, Gerritsen SL, et al. Outcomes After Distal Pancreatectomy with Celiac Axis Resection for Pancreatic Cancer: A Pan-European Retrospective Cohort Study. Ann Surg Oncol 2018;25:1440-7.

36. Mollberg N, Rahbari NN, Koch M, et al. Arterial resection during pancreatectomy for pancreatic cancer: a systematic review and meta-analysis. Ann Surg 2011;254:882-93.

37. Jegatheeswaran S, Baltatzis M, Jamdar S, et al. Superior mesenteric artery (SMA) resection during pancreatectomy for malignant disease of the pancreas: a systematic review. HPB (Oxford) 2017;19:483-90.

38. Rebelo A, Büdeyri I, Heckler M, et al. Systematic review and meta-analysis of contemporary pancreas surgery with arterial resection. Langenbecks Arch Surg 2020;405:903-19.

39. Małczak P, Sierżęga M, Stefura T, et al. Arterial resections in pancreatic cancer - Systematic review and meta-analysis. HPB (Oxford) 2020;22:961-8.

Cite this article as: Rebelo A, Ronellenfitsch U, Döbereiner J, Ukkat J, Kleeff J. Do arterial resections improve survival in pancreatic cancer?-a narrative review. Chin Clin Oncol 2021;10(5):48. doi: 10.21037/cco-21-39
40. Haines M, Chua TC, Jamieson NB, et al. Pancreatoduodenectomy With Arterial Resection for Locally Advanced Pancreatic Cancer of the Head: A Systematic Review. Pancreas 2020;49:621-8.

41. Latenstein AEJ, van der Geest LGM, Bonsing BA, et al. Nationwide trends in incidence, treatment and survival of pancreatic ductal adenocarcinoma. Eur J Cancer 2020;125:83-93.

42. Satoi S, Yamaue H, Kato K, et al. Role of adjuvant surgery for patients with initially unresectable pancreatic cancer with a long-term favorable response to non-surgical anti-cancer treatments: results of a project study for pancreatic surgery by the Japanese Society of HepatoBiliary-Pancreatic Surgery. J Hepatobiliary Pancreat Sci 2013;20:590-600.

43. Gong H, Ma R, Gong J, et al. Distal Pancreatectomy With En Bloc Celiac Axis Resection for Locally Advanced Pancreatic Cancer: A Systematic Review and MetaAnalysis. Medicine (Baltimore) 2016;95:e3061.

44. Del Chiaro M, Rangelova E, Halimi A, et al. Pancreatectomy with arterial resection is superior to palliation in patients with borderline resectable or locally advanced pancreatic cancer. HPB (Oxford) 2019;21:219-25. 